SUBJECT AREAS:

ECOLOGICAL

MODELLING

ICHTHYOLOGY

ADAPTIVE RADIATION

Received

13 November 2013

Accepted

21 February 2014

Published

10 March 2014

Correspondence and requests for materials should be addressed to

J.M.C. (julien.m. claes@uclouvain.be)

\section{OPEN Iso-luminance counterillumination drove bioluminescent shark radiation}

\author{
Julien M. Claes' ${ }^{1}$, Dan-Eric Nilsson ${ }^{2}$, Nicolas Straube ${ }^{3}$, Shaun P. Collin ${ }^{4}$ \& Jérôme Mallefet ${ }^{1}$ \\ 'Laboratoire de Biologie Marine, Earth and Life Institute, Université catholique de Louvain, 1348 Louvain-la-Neuve, Belgium, ${ }^{2}$ Lund \\ Vision Group, Lund University, 22362 Lund, Sweden, ${ }^{3}$ Department of Biology, College of Charleston, Charleston, SC 29412, USA, \\ ${ }^{4}$ The School of Animal Biology and The Oceans Institute, The University of Western Australia, Crawley, WA 6009, Australia.
}

Counterilluminating animals use ventral photogenic organs (photophores) to mimic the residual downwelling light and cloak their silhouette from upward-looking predators. To cope with variable conditions of pelagic light environments they typically adjust their luminescence intensity. Here, we found evidence that bioluminescent sharks instead emit a constant light output and move up and down in the water column to remain cryptic at iso-luminance depth. We observed, across 21 globally distributed shark species, a correlation between capture depth and the proportion of a ventral area occupied by photophores. This information further allowed us, using visual modelling, to provide an adaptive explanation for shark photophore pattern diversity: in species facing moderate predation risk from below, counterilluminating photophores were partially co-opted for bioluminescent signalling, leading to complex patterns. In addition to increase our understanding of pelagic ecosystems our study emphasizes the importance of bioluminescence as a speciation driver.

mong sharks, bioluminescence occurs in two shark families only, the Dalatiidae (kitefin sharks) and the Etmopteridae (lanternsharks), which are among the most enigmatic bioluminescent organisms ${ }^{1-3}$. Although these small deep-sea sharks encompass $\sim 12 \%$ of current shark diversity, with $>50$ described species, their luminescence is rarely observed. Moreover, contrary to the condition in other bioluminescent animals, their tiny light producing organs (photophores) are primarily controlled by hormones rather than by nerves ${ }^{4-7}$ and are found in very large numbers to form a diversity of patterns whose adaptive benefit is unclear ${ }^{1,8-13}$. Indeed, since these organs are mostly situated on the ventral side (Fig. 1a), counterillumination-a camouflage technique involving a ventral light emission that cloaks the emitter's silhouette by matching the physical characteristics of residual down-welling light ${ }^{14,15}$-is assumed to be their main function ${ }^{1,8,16,17}$. Nevertheless, counterillumination has only been experimentally demonstrated in a single coastal species, Etmopterus spinax ${ }^{18}$, and yet many bioluminescent sharks show ventral photophore-free areas (such as the 'dark collar' of the dalatiid Isistius brasiliensis ${ }^{10}$ ) and/or photophore markings on their fins, flanks and tail (in most Etmopteridae ${ }^{2,11,12,19}$; Fig. 1b) that likely perform another function. One of these photophore aggregations, the lateral photophore marking, displays clade-specific shapes (Fig. 1c) and its luminescence kinetics appears sexually dimorphic, which strongly supports a role in intraspecific recognition ${ }^{13,20}$.

A recent study suggests that bioluminescence first evolved in dalatiid sharks for counterillumination when they became part of the pelagic fauna at the Cretaceous/Tertiary transition and that etmopterids later adapted the initial counterilluminating pattern into a signalling tool when they colonized deep-water niches. Whether Dalatiidae and Etmopteridae have acquired their luminescence independently remains, however, in debate ${ }^{3,7,13,21,22}$ and the reason why some Etmopteridae such as Trigonognathus kabeyai or Etmopterus princeps lack lateral photophore markings is puzzling ${ }^{2,13}$.

Spatial deviations from the 'perfect' ventral counterilluminating pattern directly affect counterillumination efficiency ${ }^{14}$. As a consequence, complex photophore patterns (such as those with lateral photophore markings) should only occur in species less exposed to predation (from below) for which such deviations are more acceptable. In the deep pelagic environment predation risk is mainly influenced by prey detectability, which depends on the intensity of downwelling light and thus on the depth. Quantifying predation exposure is therefore difficult for marine pelagic species such as dalatiid and etmopterid sharks that evolve in a three-dimensional environment, sometimes performing daily vertical migrations ${ }^{8,10,18,23}$. However, previous work on E. spinax suggested that sharks, contrary to other counterilluminating animals ${ }^{24-26}$, emit a virtually constant luminescent output and hence are isolume followers ${ }^{4,18}$. In that context, counterilluminating sharks would be constrained to a particular depth during the daytime, where their ventral photophores are iso-luminant to downwelling solar light 

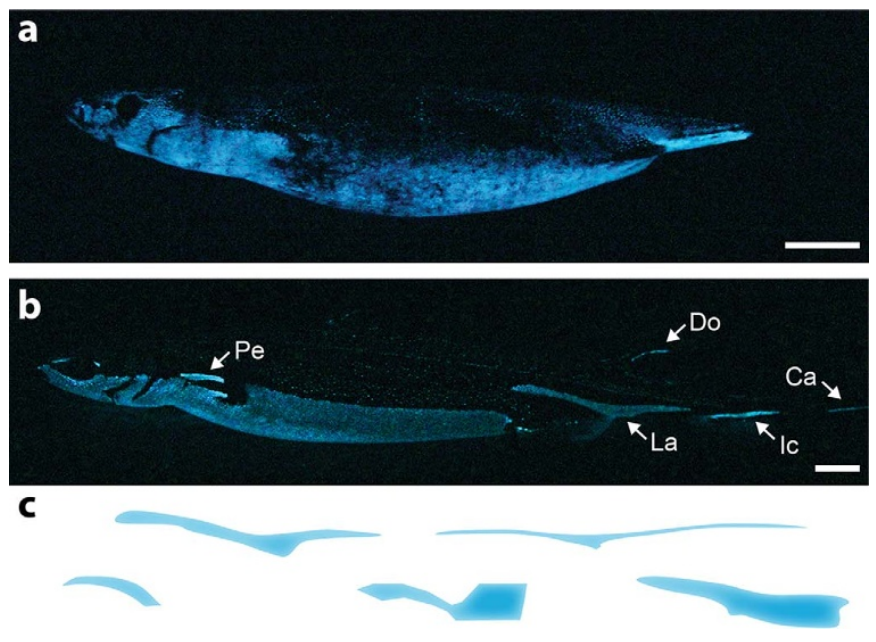

Figure 1 | Shark photophore patterns. Lateral spontaneous luminescence from (a) Squaliolus aliae and (b) E. spinax. Arrows indicate photophore markings not involved in counterillumination: Pe, pectoral; Ca, caudal; Do, dorsal; Ic, infracaudal; La, lateral. Scale bars, $2 \mathrm{~cm}$. (c) Etmopteridae lateral photophore markings (blue color) diversity illustrated by (from left to right): Centroscyllium ritteri, E. spinax, E. gracilispinis, E. lucifer and E. pusillus. Photographs by Mallefet. Drawings by Claes.

(iso-luminance depth). Vertical deviations from this depth would indeed make them detectable, jeopardizing their survival ${ }^{27}$. If confirmed, this would constitute the basis of a fixed-depth system that allows predation risk to be investigated by visual modelling, providing a way to test the putative link between predation pressure and shark photophore pattern complexity.

In this study we used an innovative morpho-physiological analysis, capture data and a recent theory for pelagic vision ${ }^{27,28}$ (i) to determine the counterilluminating capabilities of oceanic species from both luminous shark families, (ii) to test the isolume-following behaviour hypothesis and (iii) to propose an adaptive explanation for the morphological diversity of shark photophore patterns.

\section{Results}

Counterilluminating capabilities of bioluminescent sharks. Efficient pelagic counterilluminators must have a significant portion of their ventral side occupied by photophores that produce a continuous light matching the angular distribution, the wavelength and the intensity of residual downwelling light ${ }^{14,15}$.

Photophore density maps of the dalatiid Squaliolus aliae and the etmopterid Etmopterus splendidus, two species that respectively display the simplest and most complex photophore patterns of all sharks ${ }^{1,2,6,7}$, reveal unexpected organizational similarities. Indeed, in both species photogenic tissue occupy $>95 \%$ of the ventral surface area and photophore density increases centripetally from the edges to a median area of the pattern: the maximum ventral density area, which occurs at $0.45-0.55$ prepelvic length and has a width of $\sim 0.2$ interpectoral distance (Fig. 2a; Supplementary Fig. S1). These photophore patterns maximize downward emission of luminescence, allowing matching to the angular distribution of residual downwelling light. The perfect match observed for E. splendidus is achieved due to a centripetal change in photophore orientation, already observed in E. spinax ${ }^{29,30}$.

Spectral analysis of continuous spontaneous luminescence from five distinct species, two dalatiids and three etmopterids, shows wavelength peaks $\left(\lambda_{\max }\right)$ falling in the bluish part of the light spectrum (Fig. 2b). While etmopterid luminescence matches closely the residual downwelling light $\lambda_{\max }$ present in their environment (contrary to E. splendidus and E. molleri, E. spinax was caught in coastal a
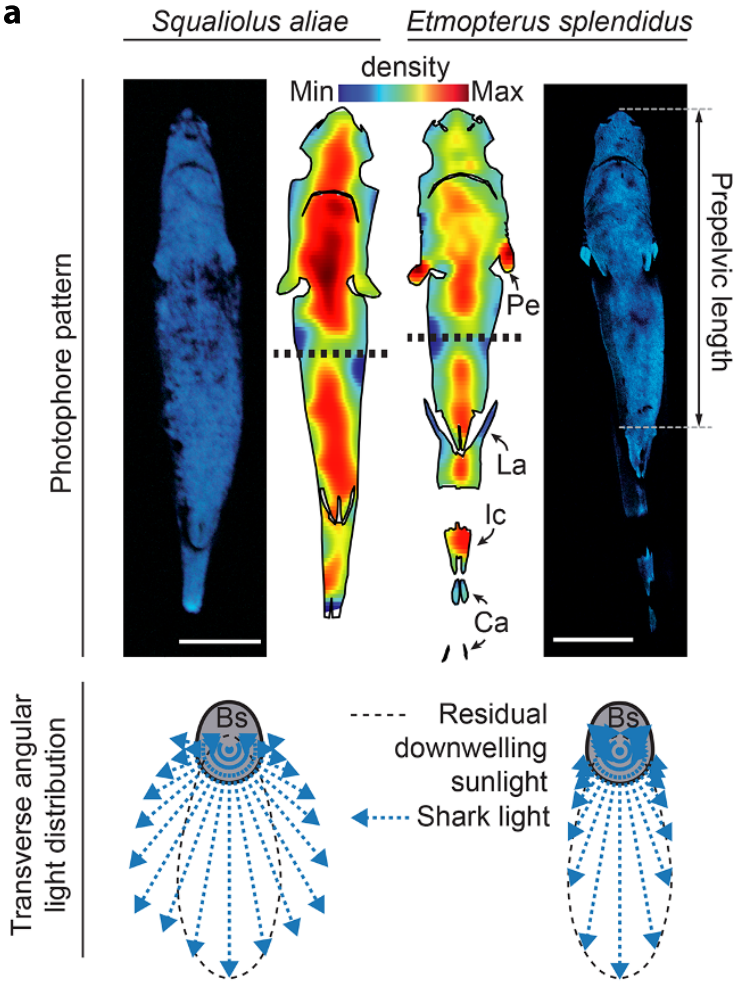

b

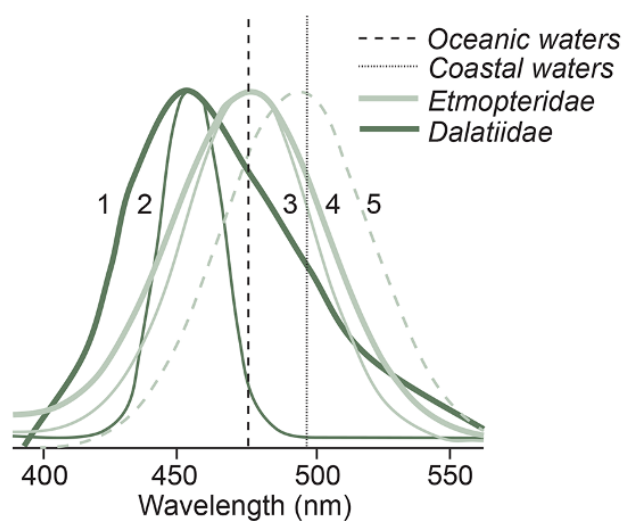

Figure $2 \mid$ Physical characteristics of shark luminescence. (a) Photophore density maps from the dalatiid S. aliae and the etmopterid E. splendidus (horizontal dashed lines indicate anterior and posterior wholemount connections with adjacent low-density artefact) with associated in vivo luminescence and transverse angular distribution (blue vectors indicate the intensity of luminescence in selected directions). Bs, body section at 0.5 prepelvic length. Luminous zone abbreviations same as in Fig. 1. Scale bars, $2 \mathrm{~cm}$. (b) Dalatiid and etmopterid emission spectra (new data combined with published spectra ${ }^{18,31}$ ) compared to published peak emission wavelength of mesopelagic coastal ${ }^{18}$ and oceanic ${ }^{32}$ waters: 1 , I. brasiliensis $\left(\lambda_{\max }=455 \mathrm{~nm}\right) ; 2$, S. aliae $\left(\lambda_{\max }=457 \mathrm{~nm}\right) ; 3$, E. splendidus $\left(\lambda_{\max }=\right.$ $476 \mathrm{~nm}) ; 4$, E. molleri $\left(\lambda_{\max }=477 \mathrm{~nm}\right) ; 5$, E. $\operatorname{spinax}\left(\lambda_{\max }=486 \mathrm{~nm}\right)$. Photographs by Mallefet. Drawings by Claes.

green waters ${ }^{18}$ ), both dalatiid species emit at shorter wavelengths than expected for perfect oceanic counterillumination ${ }^{31,32}$.

Photophore variables and iso-luminance depth. A similar maximum ventral photophore density area appears to be present in both simple and complex photophore patterns (see previous section of the results). As a consequence, we used this area as a reference area to explore differences in photophore mean diameter, photophore density and proportion of skin surface area occupied by photophores 
(PAP) of 37 bioluminescent shark species (Supplementary Data 1, Supplementary Fig. S1), which encompasses $\sim 75 \%$ of currently described photophore-bearing sharks species (Fig. 3a).

Photophore mean diameter values showed a normal distribution (mean value of $104.3 \pm 4.7$ ), ranging from $\sim 59 \mu \mathrm{m}$ in Squaliolus laticaudus to $\sim 194 \mu \mathrm{m}$ in E. spinax. Photophore density values showed a strongly left-skewed distribution (mean value of $21.2 \pm$ 3.8 units $\mathrm{mm}^{-2}$ ), ranging from $\sim 1$ unit $\mathrm{mm}^{-2}$ in Centroscyllium kamoharai to $\sim 100$ units $\mathrm{mm}^{-2}$ in S. aliae. PAP values showed a slightly left-skewed distribution (mean value of $13.8 \pm 1.7 \%$ ), ranging from $\sim 2 \%$ in C. kamoharai to $\sim 56 \%$ in T. kabeyai.

To determine if this morphological diversity leads to difference in performance and therefore difference in iso-luminance depth, we selected 21 species to perform several log-linear regressions between photophore variables and capture depth; results of these regressions are summarized in Fig. 3b. The strongest relationship was found between PAP and capture depth (Fig. 3b,c), and the slope of this relationship was not significantly different in confirmed luminous and photophore-bearing sharks [one-way analysis of covariance (ANCOVA), $F=0.048, P=0.828$ ], which supports the idea that all species included in the regression have functional photophores. However, this slope differed significantly (ANCOVA, $F=58.645, P$ $<0.001)$ from the expected slope if all shark photophores were isoluminant i.e. had the same luminescing power for a given surface (Supplementary Fig. S2). This suggests that shark photophores are not iso-luminant across PAP but instead are proportionally brighter when occupying a larger percentage of the skin (i.e. at higher PAP). In addition, the PAP - capture depth relationship also indicates a theoretical upper depth estimate for shark counterillumination in daytime of about $200 \mathrm{~m}$, i.e. when PAP would reach $100 \%$.
Predation risk modelling and shark photophore pattern diversity. The theoretical maximum predator detection distance (for a swordfish with $30 \mathrm{~mm}$ pupils) decreases with depth and becomes equal to target width at $\sim 775 \mathrm{~m}$, irrespective of target width (Fig. $4 \mathrm{a}$ ). Following a recent study, this would represent the lower limit for effective counterillumination in clear oceanic waters ${ }^{27}$. However, this value is sensitive to weather conditions and local variations in water clarity. Predators with smaller pupils will also have shorter detection distances (visual range). In addition, our model reveals that the detection distance increases linearly with target width (on a log-log scale; Fig. 4b).

Using a log-log plot of PAP against interpectoral distance for specimens of 37 distinct species, we found a significant negative relationship between these two morphological variables (Fig. 4c). In this two-dimensional morphospace, species with lateral markings clearly separate from the others; only the dalatiid I. brasiliensis is present inside the minimum convex polygon encompassing all species with lateral markings. Using PAP as a proxy of daytime occurrence depth (in oceanic waters, see Fig. 3c), we superimposed relative isometric predator detection distance lines on the graph; we show that species with complex patterns are found in a moderate risk zone of the plot (predator detection distance $\leq 1000$ interpectoral distance) and display a minimum PAP of $\sim 5 \%$.

\section{Discussion}

Ventral shark photophores and their in vivo luminescence appear well designed for camouflage by counterillumination. Moreover, this camouflage technique is possibly the sole function of dalatiid photophores since they do not form complex patterns. However, across
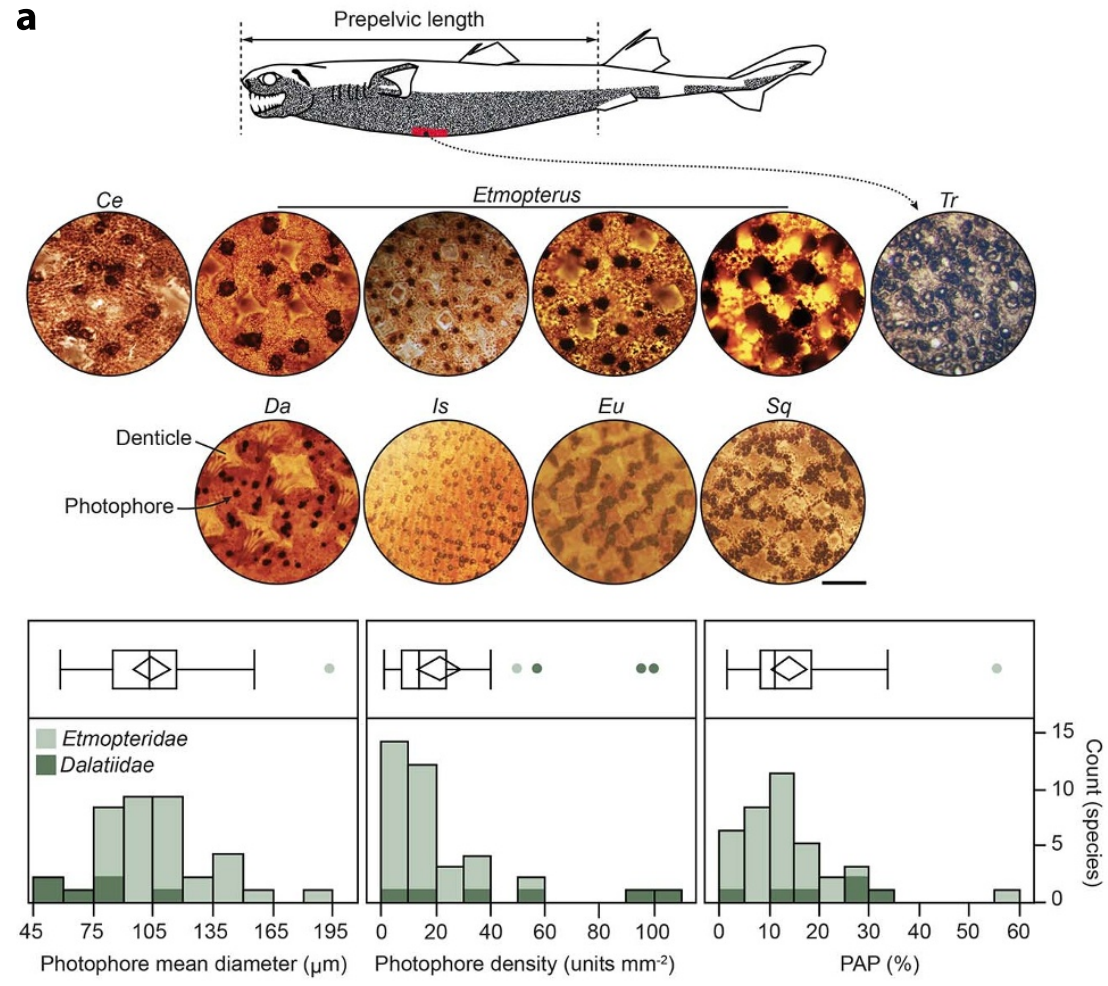
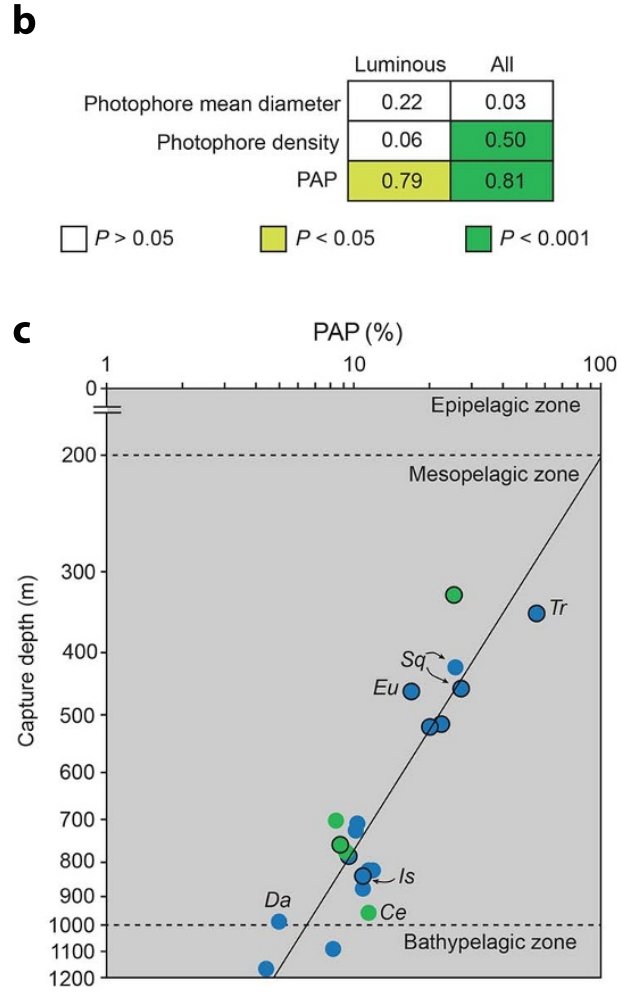

Figure $3 \mid$ Shark photophore diversity. (a) Overview of maximum ventral photophore density (red colour on top drawing) from selected representatives. Scale bar, $500 \mu \mathrm{m}$. Ce, Centroscyllium; Da, Dalatias; Eu, Euprotomicrus; Is, Isistius; Sq, Squaliolus; Tr, Trigonognathus. Box plots and histograms of photophore mean diameter, photophore density and PAP of 37 shark species from Etmopteridae (light green, $n=31$ ) and Dalatiidae (dark green, $n=6$ ) families. (b) R-square and associated $P$-value for several log-log linear regressions of photophore variables performed against capture depth. Regressions were performed either on all species for which capture depth was available $(n=21)$ or on the confirmed bioluminescent species only ('luminous', $n=9)$. (c) Log-log plot of PAP and capture depth with associated regression $\operatorname{line}\left(\log (\right.$ capture depth $\left.)=-0.564 \log (\mathrm{PAP})+2.31, r^{2}=0.81, P<0.0001, n=21\right)$ and oceanic depth zones. Blue and green dots indicate specimens captured in oceanic and coastal waters, respectively. Closed dots indicate species with confirmed bioluminescent status. Unless determined otherwise, all dots represent species of the genus Etmopterus. Photographs and drawing by Claes. 

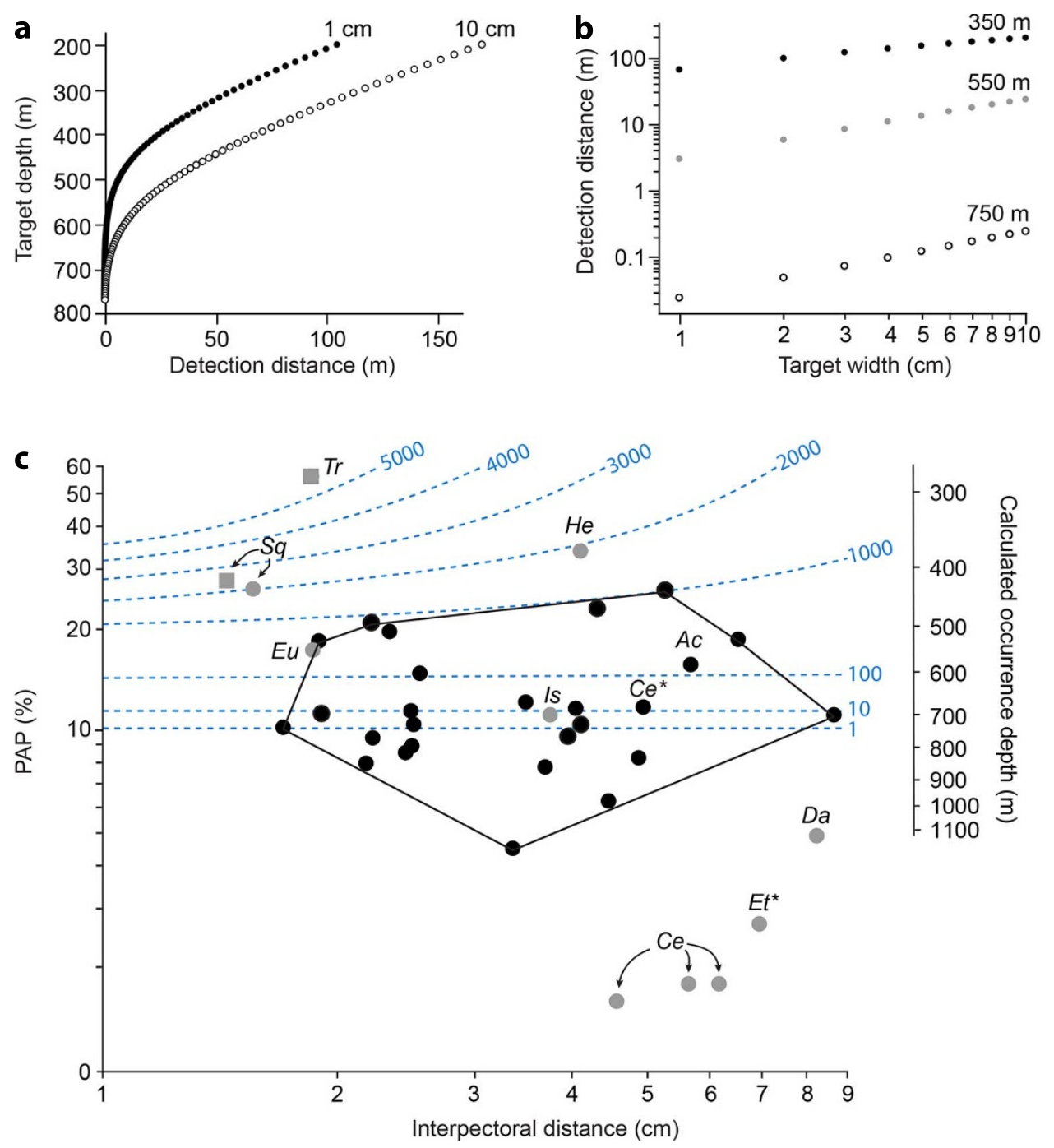

Figure $4 \mid$ Predation risk modelling. (a) Relationship between upward detection distance and target depth for two black target widths. (b) Relationship between black target width and upward detection distance for three mesopelagic depths (log-log plot). (c) Log-log plot of PAP and interpectoral distance. For clarity, regression line $(\log (\mathrm{PAP})=-0.74 \log$ (interpectoral distance $\left.)+0.583, r^{2}=0.21, P=0.0044, n=37\right)$ is not shown. Axis on the right indicates occurence depth of sharks in oceanic waters calculated from PAP using the relationship from Fig. 3c. Blue dashed lines represent isometric predator detection distance lines (standardized by interpectoral distance) according to calculated occurrence depth and interpectoral distance. These lines provide a relative idea of the predation risk encountered by the sharks (the higher the line value, the higher the relative risk). The one interpectoral distance isometric line, which occurs at $\sim 775 \mathrm{~m}$ (i.e. PAP $\sim 10 \%$ ) corresponds to the lower limit for efficient counterillumination. Note that the minimum convex polygon encompassing all species with lateral photophore markings (black symbols) only includes a single species with no markings (grey symbols), Isistius brasiliensis. This polygon is situated in a low-risk area (detection distance inferior to 1000 interpectoral distance) and contains species with a minimum PAP of $\sim 5 \%$. Square symbols indicate species for which mass captures by natural predators have been recorded. Unless determined otherwise, all dots represent species of the genus Etmopterus. Ac, Aculeola; Ce*, C. ritteri; Et* E. princeps; He, Heteroscymnoides. Other abbreviations same as in Fig. 3.

investigated specimens, Etmopteridae better match the residual downwelling sunlight than Dalatiidae, thanks to a centripetal change in photophore morphology ${ }^{29,30}$ coupled to a tuning of luminescence wavelength, via specialized filters ${ }^{15}$ and/or alternative substrates for the light-producing reaction ${ }^{33,34}$. In addition to these family-related differences, shark photophores also display an unexpected array of size, density and spatial organization. Despite this diversity, a strong, global scaling between PAP and capture depth is observed across sharks from the photic zone. This suggests that sharks are isolumefollowers and therefore are depth-constrained in daytime. Yet the exact mechanism that would allow photophores to be brighter at higher PAP remains unknown although it might be linked to high thermal rate coefficient $\left(\mathrm{Q}_{10}\right)$ for the light-producing chemical reaction and/or the use of different light-producing molecules. The key discovery that counterilluminating sharks follow isolumes provides new and fundamental understanding of shark photophore performance with major impacts on shark ecology and evolution, pelagic ecosystem studies and by-catch management strategies.

Dalatiid and etmopterid photophores are both arranged following a centripetal density gradient, and share a similar morpho$\log y^{7,8,16,17,35,36}$, physiological control ${ }^{4-7,37}$ and PAP-related performance. These striking similarities bring further support to a unique evolution of luminescence in sharks and strongly suggest that dalatiid-like counterilluminating patterns were co-opted for bioluminescent signalling in Etmopteridae. If this is true, the evolution towards complex photophore patterns under natural selection must have resulted in an increase in individual fitness. But co-opting of counterilluminating photophores for signalling involves a 
reorganization of the basal counterilluminating pattern and therefore inevitably leads to a decrease in camouflage efficiency ${ }^{14}$; this is especially true for the lateral photophore markings that occupy a large portion of the pattern. Complex photophore patterns would therefore only be expected in shark species facing relaxed predation pressure from upward-looking predators.

To the best of our knowledge, PAP represents the first morphological estimator of a pelagic organism's daytime occurrence depth. We suspect bioluminescent sharks' isolume following behaviour to be a corollary of their unique luminescence control that prevents significant changes of light intensity within a short timeline ${ }^{4,7,38}$, as was already suggested ${ }^{18}$. Other counterilluminating organisms are indeed typically able to modulate the intensity of their luminescence by several orders of magnitude and hence can occupy different isolumes in the water column ${ }^{24-26}$. The $\mathrm{PAP}$ - capture depth relationship also suggests that bioluminescent sharks can only inhabit the epipelagic zone $(0-200 \mathrm{~m})$ at night, when downwelling irradiance is low (or in coastal turbid waters). This gave us an unexpected opportunity to test if complex patterns only occur at relaxed predation risk since below $200 \mathrm{~m}$ the log radiance of downwelling light can be expected to decrease linearly with depth, which allows visual modelling to be performed ${ }^{28}$.

We showed that PAP is negatively correlated with body size, which according to our findings suggests that the size of bioluminescent sharks increases with depth. This observed trend agrees with previous studies that showed a depth-related increase in size for scavenging bony fishes ${ }^{39}$ and small-sized $(<1 \mathrm{~m} \mathrm{TL})$ sharks ${ }^{40}$. In the water column where food availability decreases with depth, a larger size is believed to represent a metabolic advantage to scavenge in the deep sea's oligotrophic environment ${ }^{39}$. However, our dataset contains only similarly aged specimens i.e. specimens close to maturity. Future work will be needed to determine if the PAP-interpectoral distance relationship is conserved across other size classes (e.g. neonates) since intraspecific variations in PAP may occur, notably in response to growth-related morphological changes ${ }^{12,41}$.

The results of our predation risk modelling (Fig. 4c) closely agree with our predictions; bioluminescent sharks do not display complex patterns when highly exposed to predation. Furthermore, T. kabeyai and S. laticaudus, for which mass captures ( $>5$ individuals found in the stomach of a single predator) were reported ${ }^{23,42}$ occupy the highrisk area of the plot, which confirms the validity of our approach. Our model also sets a lower PAP limit for lateral markings to occur, which supports the idea that signalling photophores evolved by co-option of the initial counterilluminating camouflage. Indeed, at very low PAP, the lateral photophore coverage is too low to form the cohesive lateral markings required for signalling, due to the counterillumination-optimized centripetal density gradient. Interestingly, in our morphological plot (Fig. 4c), species with complex photophore patterns separate from all the others. This trend indicates a strong evolutionary pressure to turn the counterilluminating pattern into a signalling mechanism when predation pressure is low and emphasizes the importance of bioluminescent communication for sharks in the permanent darkness of the deep sea.

The cookiecutter shark I. brasiliensis fits in the middle of the minimum convex polygon of species with lateral markings (Fig. 4c). This species occupies a peculiar position among sharks and Dalatiidae since it employs an unusual feeding mode (kleptoparasitism) and displays a pigmented photophore-free area around the neck $^{2,10}$. Ventrally, this "dog collar" disrupts the counterilluminating pattern and has been hypothesized to act as a lure by mimicking the search image of some pelagic predators on which the shark feeds ${ }^{10}$. However, no experimental or behavioural data exist to support this hypothesis and numerous common preys of the shark are either filter-feeders ${ }^{43,44}$ or megacarnivorous organisms ${ }^{44,45}$ for which such a mechanism is useless. We propose here an alternative explanation; the dark collar of I. brasiliensis might actually serve as a method of intraspecific recognition functionally analogous to the etmopterid lateral markings.

From an evolutionary point of view, shark photophores appear to be exceptional structures. They are part of an unusual isolume-constrained counterillumination system that constitutes a powerful speciation driver. Indeed, subtle changes in PAP are associated with important iso-luminance depth shifts, which can eventually lead to allopatric speciation. In addition, shark photophores also provide the basis of an intraspecific bioluminescent recognition tool that favours sympatric (or parapatric) speciation under relaxed predation risk. We assume these two complementary mechanisms to have powered the rapid radiation of bioluminescent sharks in the deep-sea ${ }^{13}$.

\section{Methods}

Photogenic pattern topography. The whole ventral photogenic tissue of formaldehyde-fixed specimens of S. aliae and E. splendidus was taken and mounted in PBS (pH 7.4) on two separate slides (anterior and posterior wholemounts). Wholemounts were observed with a Nikon Optiphot-2 compound microscope equipped with a motorized stage (MAC200; Ludl Electronic Products, USA) and a digital camera (Microfire; Optronics, USA) coupled to an IBM-PC compatible microcomputer running a stereological analysis software package (Stereo Investigator; MicroBrightField, USA). Photogenic area contours were digitized and their photophore density distribution was established using the optical fractionator method $^{46}$; wholemounts were treated as single sections. The counting frame size was $1.25 \times 1.25 \mathrm{~mm}$ and the systematic random grid spacing was $1.4 \times 1.4 \mathrm{~mm}$. Photogenic areas were manually re-connected in Adobe Illustrator ${ }^{\circledR}$ and cell count data were interpolated with R v. 2.15.2 to produce photophore density maps (Gaussian Kernel model).

In vivo luminescence characterization. Sharks were collected by rod and line off West Okinawa (Japan), at 460-520 m, in December 2011 (E. molleri, E. splendidus) and by mesopelagic nets off Southwest Taiwan (China), at 50-150 m, in July 2011 (E. splendidus and S. aliae), and transferred to seawater tanks placed in temperaturecontrolled dark rooms at the Okinawa Churaumi Aquarium (OCA) and the National Museum of Marine Biology and Aquarium (NMMBA), respectively. Our protocol, including fish sacrifice, was in accordance with institutional guidelines for experimental fish care (fish handling approval was given by the ethics boards of OCA and NMMBA).

Pictures of glowing individuals were taken in complete darkness using a digital camera (Canon 7D, Tokyo, Japan; sensitivity $6400 \mathrm{ISO}$, objective $20 \mathrm{~mm}$, aperture 2.8 , exposure time $30 \mathrm{~s}$ ). For visibility purposes, a post adjustment of brightness and contrast was applied to the entire picture using Adobe Photoshop ${ }^{\circledR}$.

The angular distribution of luminescence produced by S. aliae and E. splendidus was measured following the methodology of Claes et al. ${ }^{18}$ i.e. by measuring the relative light intensity around the shark body (on a $10 \mathrm{~cm}$ radius circle in a transversal plane at 0.5 prepelvic length) with an optical fibre coupled to a luminometer (Berthold FB12, Pforzheim, Germany).

Luminescence spectra were measured from 300 to $700 \mathrm{~nm}$ (resolution $=0.4 \mathrm{~nm}$ ) with a minispectrometer (Hamamatsu Photonics K. K. TM-VIS/NIR: C10083CA, Hamamatsu-City, Japan) and then smoothed using a Gaussian fitting for $\lambda_{\max }$ determination.

Photophore variables and daytime capture depth. Ventral skin patches $\left(\sim 0.25 \mathrm{~cm}^{2}\right)$ were excised from the centre of the maximum ventral photophore density area of specimens from 37 distinct species (Supplementary Data 1) and photographed under a binocular microscope (Leica MZ6, Wetzlar, Germany). Pictures were analysed in Image J v. 1.46 with random $2 \times 2 \mathrm{~mm}$ counting frames (except for T. kabeyai where a $1 \times 2 \mathrm{~mm}$ counting frame was used instead) to estimate photophore mean diameter, photophore density and PAP (Supplementary Fig. S1); photophore variables were independently measured twice and results were averaged to provide final values.

The relationship between these photophore variables and capture depth was investigated in some specimens, selected according to several criteria: (i) daytime capture i.e. solar elevation $\geq 0^{\circ}$ (so that little variation in downwelling solar irradiance can be assumed ${ }^{47}$ ); (ii) capture depth range (i.e. the difference between the minimum and maximum depth of a fishing event) $\leq 76$ and $\leq 50 \mathrm{~m}$ in clear oceanic and turbid coastal waters, respectively (to restrict the uncertainty on the residual solar irradiance intensity at capture depth to a single order of magnitude ${ }^{28,34}$ ) and (iii) specimen is mature or maturing i.e. neonates are excluded. When different specimens of a species were available for analysis, the specimen with the smallest capture depth range was selected (we assumed that trawled specimens were not captured during the trawling descent/ascent phase); the capture depth was defined as the median depth of the capture depth range. Solar elevation at capture locations was determined from NASA's solar calculator. Water type at capture locations was determined using SeaWIFS chlorophyll maps: we considered waters with near-surface [chlorophyll a] inferior to $0.3 \mathrm{mg} \mathrm{m}^{-3}$ to be 'oceanic' while others were classified as 'coastal'. Turbid coastal waters absorb residual light quicker than clear oceanic waters, which means that a same residual solar light level is found at shallower depth in coastal waters. To 
compare all the specimens on a standard basis, we therefore replaced coastal capture depth values by their theoretical equivalent oceanic capture depth values (for a given residual solar light level) using downwelling radiance attenuation values from Nilsson et al. ${ }^{27}$ i.e. 1.638 and $2.29 \log$ units per $100 \mathrm{~m}$ for oceanic and coastal waters, respectively ${ }^{27}$. Photophore variables were log-transformed and linearly regressed against log-transformed oceanic capture depth. Since we cannot exclude the possibility that some shark photophores may not be functional, which could induce biases in the analyses, we also conducted the same analyses considering only confirmed luminous species ${ }^{2,6,7,29,35,48-50}$. In addition, we also calculated a theoretical relationship for hypothetical sharks with photophores that would be iso-luminant across species (i.e. photophores that would produce the same light intensity for a given surface area), considering, to facilitate visual comparison with empirical data, shark photophore luminance to be equal to $T$. kabeyai photophore luminance at its occurrence depth $(284 \mathrm{~m})$, which was determined from the PAP-capture depth relationship (cfr. Fig. 3c). To calculate T. kabeyai photophore luminance, we simply divided downwelling light intensity at $284 \mathrm{~m}\left(2.649 \times 10^{14}\right.$ quanta $\mathrm{m}^{-2} \mathrm{~s}^{-1} \mathrm{sr}^{-1}$, cfr. Supplemental Information from Nilsson et al. $\left.{ }^{28}\right)$ by $T$. kabeyai. PAP $(\sim 56 \%)$, which gave us a shark photophore luminance value per PAP unit $\left(4.73 \times 10^{12}\right.$ quanta $\mathrm{m}^{-2}$ $\left.\mathrm{s}^{-1} \mathrm{sr}^{-1} \%^{-1}\right)$. The PAP of each other shark was finally multiplied by this luminance value and compared with depth-related downwelling light intensity (cfr. Supplemental Information from Nilsson et al. ${ }^{28}$ ) to determine theoretical occurrence depth of other sharks.

\section{Predation risk modelling. To quantify the adaptive advantage of}

counterillumination in sharks, we used a recent theory for vision in pelagic habitats ${ }^{28}$ to calculate the maximum detection distance at which a predator could see (upwardlooking direction) etmopterid and dalatiid sharks if these sharks did not have counterilluminating photophores (hence appeared as black targets). According to this theory, three main parameters are required to calculate observer detection distance (see equation 7 in Supplemental Information from ref. 28): target diameter, observer pupil diameter and observer depth. Target diameter was assumed to correspond to interpectoral distance since from below, this distance provides a feeding-state independent proxy for the maximum width of a circular pixel fitting into the silhouette of a bioluminescent shark (Supplementary Fig. S3). Observer pupil diameter was set to $30 \mathrm{~mm}$, the maximum value reported for the swordfish (Xiphias gladius $^{51}$ that we chose as a reference predator since (i) large piscivorous fishes have been reported to prey massively on some bioluminescent sharks ${ }^{23,42}$ and (ii) this fish, which forages into the mesopelagic zone $e^{52}$, also displays the upper bound value for fish pupil diamete ${ }^{28}$ hence, according to our model, provides a maximum theoretical detection distance value for a predatory fish. Photoreceptor cell diameter, which plays a negligible role in the modelling, was set to $3 \mu \mathrm{m}$. We calculated observer depth from target depth, which corresponds to observer depth - detection distance. We finally performed a log-log plot of PAP (proxy for target depth, see PAP-capture depth relationship from Fig. 3c) against interpectoral distance (proxy for target pixel diameter) for specimens of 37 distinct species with superimposed isometric detection distance lines. We expressed detection distance in relative value i.e. as a multiple of interpectoral distance to account for prey size, which directly impacts prey escape speed and hence predation risk.

Statistics. Slope comparisons were performed using ANCOVAs. All statistical analyses were performed in JMP ${ }^{\circledR} \mathrm{v}$. 10 and considered to be significant at the 0.05 level. Mean value of photophore diameter, photophore density and PAP are indicated \pm SEM.

1. Reif, W.-E. Functions of scales and photophores in mesopelagic luminescent sharks. Acta. Zool. 66,111-118 (1985).

2. Compagno, L., Dando, M. \& Fowler, S. A field guide to the sharks of the world (HarperCollins, London, 2005).

3. Claes, J. M. \& Mallefet, J. in Bioluminescence in Focus - a Collection of Illuminating Essays (ed. Meyer-Rochow, V. B.) 51-65 (Research Signpost, Kerala, 2009).

4. Claes, J. M. \& Mallefet, J. Hormonal control of luminescence from lanternshark (Etmopterus spinax) photophores. J. Exp. Biol. 212, 3684-3692 (2009).

5. Claes, J. M. \& Mallefet, J. Control of luminescence from lantern shark (Etmopterus spinax) photophores. Commun. Integr. Biol. 4, 1-3 (2011).

6. Claes, J. M., Sato, K. \& Mallefet, J. Morphology and control of photogenic structures in a rare dwarf pelagic shark (Etmopterus splendidus). J. Exp. Mar. Biol. Ecol. 406, 1-5 (2011)

7. Claes, J. M., Ho, H.-C. \& Mallefet, J. Control of luminescence from pygmy shark (Squaliolus aliae) photophores. J. Exp. Biol. 215, 1691-1699 (2012).

8. Hubbs, C. L., Iwai, T. \& Matsubara, K. External and internal characters, horizontal and vertical distribution, luminescence, and food of the dwarf pelagic shark, Euprotomicrus bispinatus. Bull. Scripps Inst. Oceanogr. 10, 1-64 (1967).

9. Springer, S. \& Burgess, G. H. Two new dwarf dogsharks (Etmopterus, Squalidae) found off the Caribbean coast of Columbia. Copeia 3, 584-591 (1985).

10. Widder, E. A. A predatory use of counterillumination by the squaloid shark, Isistius brasiliensis. Env. Biol. Fish 53, 257-263 (1998).

11. Last, P. R., Burgess, G. H. \& Séret, B. Description of six new species of lanternsharks of the genus Etmopterus (Squaloidea: Etmopteridae) from the Australasian region. Cybium 26, 203-223 (2002)

12. Claes, J. M. \& Mallefet, J. Ontogeny of photophore pattern in the velvet belly lantern shark, Etmopterus spinax. Zoology 112, 433-441 (2009).
13. Straube, N., Iglésias, S. P., Sellos, D. Y., Kriwet, J. \& Schliewen, U. K. Molecular phylogeny and node time estimation of bioluminescent lantern sharks (Elasmobranchii: Etmopteridae). Mol. Phylogenet. Evol. 56, 905-917 (2010).

14. Johnsen, S., Widder, E. A. \& Mobley, C. D. Propagation and perception of bioluminescence: factors affecting counterillumination as a cryptic strategy. Biol. Bull. 207, 1-16 (2004).

15. Denton, E. J., Herring, P. J., Widder, E. A., Latz, M. F. \& Case, J. F. The role of filter in the photophore of oceanic animals and their relation to vision in the oceanic environment. Proc. Roy. Soc. B 225, 63-97 (1985).

16. Seigel, J. A. Revision of the dalatiid shark genus Squaliolus: anatomy, systematics, ecology. Copeia 1978, 602-614 (1978).

17. Claes, J. M. \& Mallefet, J. Early development of bioluminescence suggests camouflage by counter-illumination in the velvet belly lantern shark Etmopterus spinax (Squaloidea: Etmopteridae). J. Fish Biol. 73, 1337-1350 (2008).

18. Claes, J. M., Aksnes, D. L. \& Mallefet, J. Phantom hunter of the fjords: counterillumination in a shark (Etmopterus spinax). J. Exp. Mar. Biol. Ecol. 388, 28-32 (2010).

19. Claes, J. M., Dean, M. N., Nilsson, D.-E., Hart, N. S. \& Mallefet, J. A deepwater fish with 'lightsabers' - dorsal spine-associated luminescence in a counterilluminating lanternshark. Sci. Rep. 3, 1308 (2013).

20. Claes, J. M. \& Mallefet, J. Functional physiology of lantern shark (Etmopterus spinax) luminescent pattern: differential hormonal regulation of luminous zones. J. Exp. Biol. 213, 1852-1858 (2010).

21. Klug, S. \& Kriwet, J. Timing of deep-sea adaptation in dogfish sharks: insights from a supertree of extinct and extant taxa. Zool. Scr. 39, 331-342 (2010).

22. Naylor, G. J., Caira, J. N., Jensen, K., Rosana, K. A., Straube, N. \& Lakner, C. in The Biology of Sharks and Their Relatives (eds. Carrier, J. C., Musak, J. A. \& Heithaus, M. R.) 31-56 (2012).

23. Yano, K., Mochizuki, K., Tsukada, O. \& Suzuki, K. Further description and notes of natural history of the viper dogfish, Trigonognathus kabeyai from the Kumanonada Sea and the Ogasawara Islands, Japan (Chondrichthyes: Etmopteridae). Ichthyol. Res. 50, 251-258 (2003).

24. Warner, J. A., Latz, M. I. \& Case, J. F. Cryptic bioluminescence in a midwater shrimp. Science 203, 1109-1110 (1979).

25. Young, R. E., Kampa, E. M., Maynard, S. D., Mencher, F. M. \& Roper, C. F. Counterillumination and the upper depth limits of midwater animals. Deep Sea Res. 27, 671-691 (1980).

26. Jones, B. W. \& Nishiguchi, M. K. Counterillumination in the Hawaiian bobtail squid, Euprymna scolopes Berry (Mollusca: Cephalopoda). Mar. Biol. 144, 1151-1155 (2004).

27. Nilsson, D.-E., Warrant, E. \& Johnsen, S. Computational visual ecology in the pelagic realm. Phil. Trans. R. Soc. B 369, 20130038 (2014).

28. Nilsson, D.-E., Warrant, E. J., Johnsen, S., Hanlon, R. \& Shashar, N. A unique advantage for giant eyes of giant squid. Curr. Biol. 22, 683-688 (2012).

29. Hickling, C. F. The luminescence of the dogfish, Spinax niger Cloquet. Nature 121, 280-281 (1928).

30. Claes, J. M. Function and control of luminescence from lanternshark (Etmopterus spinax) photophores. Ph. D. Thesis. Université catholique de Louvain (Belgium, 2010).

31. Herring, P. J. The spectral characteristics of luminous marine organisms. Proc. Roy. Soc. B 220, 183-217 (1983).

32. Johnsen, S., Frank, T. M., Haddock, S. H., Widder, E. A. \& Messing, C. G. Light and vision in the deep-sea benthos: I. Bioluminescence at 500-1000 $\mathrm{m}$ depth in the Bahamian Islands. J. Exp. Biol. 215, 3335-3343 (2012).

33. Nakatsu, T. et al. Structural basis for the spectral difference in luciferase bioluminescence. Nature 440, 372-376 (2006)

34. Widder, E. A. Bioluminescence in the ocean: origins of biological, chemical and ecological diversity. Science 328, 704-708 (2010).

35. Oshima, H. Some observations on the luminous organs of fishes. J. Coll. Sci., Imp. Univ., Tokyo 27, 1-25 (1911).

36. Iwai, T. Luminous organs of the deep-sea squaloid shark, Centroscyllium ritteri Jordan and Fowler. Pac. Sci. 15, 51-54 (1960).

37. Claes, J. M. \& Mallefet, J. The lantern shark's light switch: turning shallow water crypsis into midwater camouflage. Biol. Lett. 6, 685-687 (2010).

38. Claes, J. M., Krönström, J., Holmgren, S. \& Mallefet, J. Nitric oxide in the control of luminescence from lantern shark (Etmopterus spinax) photophores. J. Exp. Biol. 213, 3005-3011 (2010).

39. Collins, M. A., Bailey, D. M., Ruxton, G. D. \& Priede, I. G. Trends in body size across an environmental gradient: a differential response in scavenging and nonscavenging demersal deep-sea fish. Proc. Roy. Soc. B 272, 2051-205 (2005).

40. Priede, I. G. et al. The absence of sharks from abyssal regions of the world's oceans. Proc. Roy. Soc. B 273, 1435-1441 (2006).

41. Schmidt-Nielson, K. Scaling: Why is Animal Size so Important? (Cambridge University Press, Cambridge, 1984).

42. Sadowsky, V., Amorim, A. D. \& Arfelli, C. A. Record of unusual number of dwarf shark, Squaliolus laticaudus, off the south coast of Brazil. Bol. Inst. Pesca 12, 45-50 (1985).

43. Berra, T. M. \& Hutchins, J. B. A specimen of megamouth shark, Megachasma pelagios (Megachasmidae) from Western Australia. Rec. West. Aust. Mus. 14, 651-656 (1990). 
44. Dwyer, S. L. \& Visser, I. N. Cookie cutter shark (Isistius sp.) bites on cetaceans, with particular reference to killer whales (orca)(Orcinus orca). Aquat. Mamm. 37, 111-138 (2011).

45. Hoyos-Padilla, M., Papastamatiou, Y. P., O’Sullivan, J. \& Lowe, C. G. Observation of an attack by a cookiecutter shark (Isistius brasiliensis) on a white shark (Carcharodon carcharias). Pac. Sci. 67, 129-134 (2013).

46. West, M. J., Slomianka, L. \& Gundersen, H. J. G. Unbiased stereological estimation of the total number of neurons in the subdivisions of the rat hippocampus using the optical fractionator. Anat. Rec. 231,182-497 (1991).

47. Johnsen, S. Optics of Life: A Biologist's Guide to Light in Nature. (Princeton University Press, 2012).

48. Bennet, F. B. Narrative of a whaling voyage around the world from the year 1833 to 1836 (Richard Bentley, London, 1840).

49. Dickens, D. A. G. Observations on Euprotomicrus. Mar. Obs. 26, 73 (1956).

50. Castro, J. I. The Sharks of North America (Oxford University Press, 2011).

51. Fritsches, K. A., Brill, R. W. \& Warrant, E. J. Warm eyes provide superior vision in swordfishes. Curr. Biol. 15, 55-58 (2005).

52. Takahashi, M., Okamura, H., Yokawa, K. \& Okazaki, M. Swimming behavior and migration of a swordfish recorded by an archival tag. Mar. Freshwater Res. 54, 527-534 (2003).

\section{Acknowledgments}

We thank H.-C. Ho and K. Sato as well as the staffs of National Museum of Marine Biology and Aquarium and Okinawa Churaumi Aquarium for help in live specimen collection and maintenance. Access to preserved collection specimens and their capture information would not have been possible without the help of G. Burgess, R. Causse, G. Duhamel, A. Graham, H.-C. Ho, T. Kawai, S. Morrison, R. Robins, K. Sato, U. Schliewen, B. Séret, R. Singer, M. Stehmann, R. Thiel, S. Weigmann and H. Zidowitz. We also acknowledge E. Garza Gisholt for his help in using his R script for the creation of photophore maps.
Financial support (including grant: 1.5.278.08) was provided by the Fonds National de la Recherche Scientifique (FNRS, Belgium) to J.M.C. (postdoctoral researcher at FNRS) and J.M. (research associate at FNRS). D.-E.N. acknowledge The Swedish Research Council (grant: 2011-4768) and the Knut and Alice Wallenberg Foundation (grant: Ultimate Vision). G.J.P. Naylor and the National Science Foundation are gratefully acknowledged for support to N.S. (grant: NSF, DEB 1132229). Part of the research was supported by the Australian Research Council (grant: DP110103294) to S.P.C. This is a contribution to the Biodiversity Research Center (BDIV) and to the Centre Interuniversitaire de Biologie Marine (CIBIM).

\section{Author contributions}

J.M.C. and J.M. collected live sharks, took photographs and measured in vivo luminescence physical characteristics. J.M.C. performed the morphological measurements of preserved specimens with the assistance of N.S. and S.P.C. D.E.N. and J.M.C. established the predation risk modelling. J.M.C. performed the analyses and wrote the manuscript. All authors discussed the results and commented on the manuscript at all stages.

\section{Additional information}

Supplementary information accompanies this paper at http://www.nature.com/ scientificreports

Competing financial interests: The authors declare no competing financial interests.

How to cite this article: Claes, J.M., Nilsson, D.-E., Straube, N., Collin, S.P. \& Mallefet, J. Iso-luminance counterillumination drove bioluminescent shark radiation. Sci. Rep. 4, 4328; DOI:10.1038/srep04328 (2014)

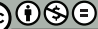

This work is licensed under a Creative Commons Attribution-

NonCommercial-NoDerivs 3.0 Unported license. To view a copy of this license, visit http://creativecommons.org/licenses/by-nc-nd/3.0 